\title{
BMJ Open Association between television viewing and overweight and obesity among women of reproductive age in Timor- Leste: evidence from the demographic health survey 2016
}

Animesh Talukder (1) , ${ }^{1}$ Rajat Das Gupta (1) , ${ }^{1,2}$ Mohammad Rashidul Hashan (D) ," Shams Shabab Haider, ${ }^{1}$ Ibrahim Hossain Sajal, ${ }^{1,4}$ Malabika Sarker ${ }^{1,5}$

To cite: Talukder A, Das Gupta R, Hashan MR, et al. Association between television viewing and overweight and obesity among women of reproductive age in Timor-Leste: evidence from the demographic health survey 2016. BMJ Open 2021;11:e045547. doi:10.1136/ bmjopen-2020-045547

- Prepublication history and additional supplemental material for this paper are available online. To view these files, please visit the journal online. (http://dx.doi.org/10.1136/ bmjopen-2020-045547).

AT and RDG contributed equally.

Received 04 0ctober 2020 Accepted 16 July 2021

Check for updates

(C) Author(s) (or their employer(s)) 2021. Re-use permitted under CC BY-NC. No commercial re-use. See rights and permissions. Published by BMJ.

For numbered affiliations see end of article.

Correspondence to

Dr Animesh Talukder;

animesh.talukder@bracu.ac.bd

\section{ABSTRACT}

Objective This study aimed to assess the possible relationship between television viewing and overweight and obesity among Timorese women of reproductive age. Methods This cross-sectional study analysed the TimorLeste Demographic and Health Survey 2016 dataset. A weighted sample of 11398 Timorese women aged 15-49 years was chosen using a two-stage stratified random sampling technique. Asian criteria-based body mass index (BMI) cut-offs were used to define overweight (BMI 23.0 to $<27.5 \mathrm{~kg} / \mathrm{m}^{2}$ ) and obesity $\left(\mathrm{BMl} \geq 27.5 \mathrm{~kg} / \mathrm{m}^{2}\right)$. Frequency of TV viewing was categorised into three groups: (1) not at all, (2) less than once a week and (3) at least once a week. Multilevel ordered logistic regression was performed to identify the correlates of overweight and obesity. Both crude and adjusted odds ratios (AOR) along with a $95 \% \mathrm{Cl}$ were calculated to show the strength of association.

Results Among 11398 respondents, 19.4\% were overweight or obese (overweight: $15.7 \%$ and obese: $3.8 \%$ ). Although about half of the respondents reportedly did not watch TV at all, just over two-thirds watched TV at least once a week. Women who watched TV at least once a week were found to have 1.3 times the odds of being overweight or obese compared with those who never watched TV (AOR: $1.3,95 \% \mathrm{Cl}: 1.1$ to $1.5 ; \mathrm{p}<0.001$ ). However, when stratified by settlement type, the statistical significance stood for the rural women only (AOR: 1.5, $95 \% \mathrm{Cl}: 1.2$ to $1.8 ; \mathrm{p}<0.001)$, after adjusting for the covariates.

Conclusion Watching TV at least once a week was found to be a significant correlate of overweight and obesity in rural Timorese women of reproductive age. Further studies need to be undertaken to assess physical activity, sedentary and dietary patterns to clarify the possible mechanism through which TV viewing may influence BMI in those groups.

\section{INTRODUCTION}

High body mass index (BMI) (ie, overweight and obesity) is considered the fourth leading risk factor of disability worldwide when ranked by disability-adjusted life-years. ${ }^{1}$
Strengths and limitations of this study

- To the best of our knowledge, this study is the first to assess the relationship of TV viewing frequency with overweight and obesity in Timor-Leste.

- This study analysed a nationally representative survey dataset with a high response rate (97\%), hence the findings are generalisable to a great extent.

- The survey utilised validated questionnaires, calibrated measurement tools and well-trained enumerators and technicians, limiting the chance of measurement error.

- A self-reported measurement of TV viewing frequency/duration may have led to a reporting bias.

- Some of the potentially important behavioural risk factors (eg, inactivity or sedentary status, poor dietary habit, tobacco and alcohol consumption) could not be adjusted for in the multivariable analyses to discern the strength of the independent relationship between TV viewing and overweight and obesity, as information regarding those risk factors was not collected in the survey.

Epidemiological studies throughout the years have found associations between overweight and obesity and many notable chronic diseases, such as hypertension, cardiovascular and cerebrovascular diseases, type 2 diabetes mellitus, ${ }^{2} 3$ chronic kidney disease, a number of cancers, ${ }^{4}$ a group of musculoskeletal disorders ${ }^{5}{ }^{6}$ and some forms of respiratory diseases. ${ }^{7}$ In particular, obesity is suggestive of contributing to severe forms of infection amid the COVID-19 pandemic. ${ }^{8}$ Among the COVID-19-affected groups that needed critical care, a higher prevalence of obesity was observed. ${ }^{910}$ Additionally, a significant inverse correlation was found between age and BMI among the affected individuals, suggesting younger patients' being more likely to be obese. ${ }^{11}$ Moreover, obesity may 
also lead to psychosocial impairment ${ }^{12}$ and a significant reduction in both health-related quality of $\operatorname{life}^{13}$ and overall life expectancy. ${ }^{14}$ Furthermore, it poses drastic economic implications as well, as highlighted by a systematic review in 2011, which showed obese people enduring $30 \%$ excess medical expenses, compared with their normal weight counterparts. ${ }^{15}$ This condition, though currently affecting over a third of the global population, ${ }^{16}$ is largely preventable. ${ }^{12}$ Even a modest reduction of body weight was found to be associated with meaningful risk attenuation for hypertension, hyperglycaemia, dyslipidaemia and many other comorbidities. ${ }^{17}$ Of those who suffer the most, the women of reproductive age are of particular importance. Apart from the aforementioned complications, overweight and obesity pose an additional burden on women of reproductive age due to obstetric complications, such as gestational diabetes mellitus and pre-eclampsia, surgical and anaesthetic complications, as well as an increased chance of miscarriage; these obstetric risks are more common in low-resource settings, which have a substandard continuum of care to deal with the existing obstetric and gynaecological problems. ${ }^{18} 19$

Globally, both developed and underdeveloped countries are experiencing an escalating prevalence of overweight and obesity. ${ }^{20}$ Due to demographic and epidemiological transition, obesity and overweight, once considered an archetypal high-income country problem, are becoming dramatically prevalent even in the least developed countries. Timor-Leste (also known as East Timor), despite only gaining international recognition as a sovereign nation in 2002, has continued to struggle to achieve economic solvency amid the ongoing massive rebuilding ${ }^{21}$ and has remained one of the least developed countries in the world thus far. ${ }^{22}$ Although Timor-Leste has been experiencing a massive burden of undernourishment ${ }^{23}$ a looming double burden of malnutrition due to epidemiological transition cannot be ruled out. This might pose a tremendous challenge for the country's healthcare system, especially when the country is still far off course from meeting its nutrition targets; that is evident from the fact that more than $40 \%$ of Timorese women of reproductive age are anaemic. ${ }^{23}$ On the contrary, almost $5 \%$ of the women of Timor-Leste are reportedly obese ${ }^{23}$; however, the proportion of overweight and obesity among the women of reproductive age is not known. Therefore, it is important to know the prevalence and correlates of these conditions in this age group.

Spending time watching TV was found to be associated with excess body weight among both men and women in prospective studies. ${ }^{245}$ Some propositions that may elucidate this relationship are: (1) replacement of the daily recommended as well as discretionary physical activity time with TV watching time, ${ }^{26}$ (2) sleep deprivation ${ }^{27}$ and (3) promotion of unhealthy dietary choices $^{26}$ that contribute to weight gain. Women of reproductive age were found to be sedentary to an alarming extent in a large epidemiological study. ${ }^{28}$ Moreover, sedentariness has been linked with idiopathic infertility of women in a case-control study. ${ }^{29} \mathrm{TV}$ watching was found to be a correlate of overweight and obesity in Indonesia, a neighbouring country of Timor-Leste. ${ }^{30}$ However, this relationship is yet to be studied in the context of Timor-Leste. This study, therefore, aimed to assess the relationship between TV viewing and overweight and obesity among Timorese women of reproductive age. Furthermore, previous studies stratified this relationship by type of settlement (urban/rural) and found a stronger association among the TV viewing groups in urban areas. ${ }^{19} 3132$ This study, therefore, additionally tries to elucidate that hypothesis in the context of Timor-Leste.

\section{METHODS \\ Study setting}

Timor-Leste is a lower-middle-income country in Southeast Asia. The nation gained independence in 1999 after a long conflict with Indonesia. ${ }^{33}$ In 2018, the total population was 1.2 million, with an annual growth rate of $2 \%{ }^{34}$ Approximately, three-fourths of the population $(74 \%)$ reside in rural areas. ${ }^{35}$ Health indicators in this country are one of the poorest in Southeast Asia. ${ }^{33}$ Timor-Leste has a three-tiered public health system. The primary healthcare system consists of health posts and community health centres, whereas the secondary and tertiary health systems consist of district hospitals and a national hospital, respectively. ${ }^{36}$ Currently, there are eights doctors and nine nurses per 10000 people in Timor-Leste. ${ }^{37}$

\section{Study design}

This study analysed the Timor-Leste Demographic Health Survey (TLDHS) 2016 dataset. $^{38}$ The TLDHS was a nationally representative cross-sectional survey implemented between September and December of 2016 by the General Directorate of Statistics under the Ministry of Planning and Finance. The Ministry of Health also collaborated in the implementation of the survey. ICF, with the financial support of the United States Agency for International Development (USAID), provided technical support for the survey. ${ }^{38}$ A stratified cluster random sampling technique was applied for the selection of households for data collection. The 2015 Timor-Leste Population and Housing Census acted as the sampling frame for the TLDHS. The sampling was done in two stages. Initially, 455 enumeration areas (EAs) (urban: 129 and rural: 326) were selected based on the probability proportional to EA size. At the second stage, a fixed number of households $(n=26)$ were selected randomly from each of the selected EAs. In total, 11829 households were selected. However, only 11660 of those households were found to be occupied. The final data were collected from 11502 households (urban: 3215 households and rural: 8287 households), which yielded a $99 \%$ response rate. Women aged 15-49 years, who were either permanent residents or resided in the households overnight before the survey, were interviewed. The response rate among the eligible women was $97 \%$. The detailed methods including 
sampling and data collection procedure of the TLDHS 2016 were published previously. ${ }^{35}$

\section{Data collection and measurements}

Data were collected through a standard pretested women's questionnaire developed by the DHS programme. The questionnaire was modified according to the local context. It was developed in English, then translated into Tetum (local language of Timor-Leste). Trained interviewers collected the data via face-to-face interviews. Tablet computers were used for the questionnaire-based survey. Anthropometric measurements were conducted using calibrated measuring boards and calibrated Seca scales. $^{35}$

\section{Study population, variables, and inclusion criteria}

The target population of this study were Timorese women aged 15-49 years. Women who were either pregnant or gave birth in the 2 months prior to the survey were excluded. The primary study variables of interest for this study were high BMI (ie, overweight and obesity) and frequency of TV viewing. Asian criteria-based BMI cutoffs were used to categorise BMI in order to allocate a more accurate association between body fat percentage and BMI for the target population. ${ }^{39}$ The following categories of BMI were used: (1) normal and/or underweight (BMI: $<23.0 \mathrm{~kg} / \mathrm{m}^{2}$ ), (2) overweight (BMI: 23.0 $\mathrm{kg} / \mathrm{m}^{2}$ to $<27.5 \mathrm{~kg} / \mathrm{m}^{2}$ ) and (3) obesity (BMI: $\geq 27.5 \mathrm{~kg} /$ $\mathrm{m}^{2}$ ). The frequency of TV watching was categorised into three groups: (1) not at all, (2) less than once a week and (3) at least once a week. ${ }^{35}$ Based on the literature, the following covariates were considered: age, place of residence, municipality of residence, marital status, educational attainment, current employment status, household wealth status, parity and the number of household members. Based on the available literature, age was categorised into the following three categories: (1) 15-24 years, (2) 25-34 years and (3) 35-49 years. ${ }^{40}$ The number of household members was dichotomised, based on the median value of 6 , into two categories: $(1) \leq 6$ and $(2)>6$. Wealth index was calculated through principal component analysis technique based on household construction material, water source and sanitation facility, and possession of assets like bicycles, TVs, etc. Household wealth status was derived after dividing this wealth index into quintiles. ${ }^{3541}$ The study variables along with their categories are outlined in online supplemental table 1.

\section{Data analysis}

At first, the background characteristics of the respondents were determined by descriptive analysis and the findings were presented in frequency and percentage. Then, a $\chi^{2}$ test was conducted to find the possible relationship of BMI with the frequency of TV viewing and other covariates. During the analyses, the sample weight used in the TLDHS was adjusted for. To find the possible correlates of overweight and obesity, multivariable multilevel ordered logistic regression was carried out. The multilevel regression was performed considering the hierarchical nature of the DHS data ${ }^{42-44}$ Both crude odds ratio (COR) and adjusted odds ratio (AOR) were reported with 95\% CI. Additionally, we performed multilevel ordered logistic regression analyses considering normal BMI $\left(18.5-22.99 \mathrm{~kg} / \mathrm{m}^{2}\right)$ as the reference category. Moreover, linear regression analyses were conducted to assess the relationship between BMI and the frequency of watching TV. Furthermore, the association between underweight $\left(<18.5 \mathrm{~kg} / \mathrm{m}^{2}\right)$ (compared with normal BMI) and frequency of watching TV was assessed. Variance inflation factor (VIF) was used to determine possible multicollinearity among the covariates. The existence of significant multicollinearity was defined by a VIF greater than $5,{ }^{45}$ however, no significant multicollinearity was detected. All the statistical analyses were performed through Stata V.14.0 (StataCorp).

\section{Reporting checklist}

The STROBE cross-sectional checklist ${ }^{46}$ was utilised while writing the manuscript.

\section{Patient and public involvement}

No patient involved.

\section{Findings prevalence and distribution of BMI categories}

This study analysed the data from a weighted sample of 11398 Timorese women of reproductive age (15-49 years) to assess the possible relationship between frequency of TV viewing and being overweight or obese. The prevalences of overweight and obesity among the respondents were found to be $15.7 \%$ (95\% CI: $14.7 \%$ to $16.7 \%$ ) and $3.8 \%$ (95\% CI: $3.3 \%$ to $4.3 \%$ ), respectively, whereas the combined prevalence of both overweight and obesity was $19.4 \%$ (95\% CI: $18.3 \%$ to $20.6 \%$ ).

The distribution of BMI across different categories of respondents' background characteristics is outlined in table 1 . The majority of women were between 15 and 24 years of age $(41.2 \%)$, hailed from rural areas $(67.1 \%)$ and belonged to the municipality of Dili $(25.1 \%)$. Although just over one-fifth $(21.8 \%)$ of the respondents did not receive any formal education, more than half $(52.0 \%)$ completed secondary education. Around two-thirds of the respondents $(65.8 \%)$ were in employment at the time of the survey. In terms of wealth status, approximately, a quarter of the respondents $(24.2 \%)$ belonged to the 'richest' quintile of the wealth index. Around half of the respondents $(42.4 \%)$ were nulliparous, whereas $29.6 \%$ had a parity of more than three. Around half of the respondents $(47.7 \%)$ had more than six members in their households. Although $41.2 \%$ of the respondents, reportedly, did not watch TV at all, $38.0 \%$ watched TV at least once a week.

\section{Relationship of overweight and obesity with background characteristics}

Statistically significant differences were found among the BMI of women across all the covariates, except the number of household members. Prevalence of overweight and 
Open access

Table 1 Distribution of BMl across categories of background characteristics of the respondents $(N=11398)$

BMI status (\%)

\begin{tabular}{|c|c|c|c|c|c|}
\hline Background characteristics & $\mathbf{N}$ & $\%$ & BMI $<23 \mathrm{~kg} / \mathrm{m}^{2}$ & $23 \mathrm{~kg} / \mathrm{m}^{2} \geq \mathrm{BMI}<27.5 \mathrm{~kg} / \mathrm{m}^{2}$ & $\mathrm{BMI} \geq 27.5 \mathrm{~kg} / \mathrm{m}^{2}$ \\
\hline \multicolumn{6}{|l|}{ Age group (years) $)^{*}$} \\
\hline $15-24$ & 4694 & 41.2 & 91.2 & 7.4 & 1.4 \\
\hline $25-34$ & 3216 & 28.2 & 75.6 & 19.8 & 4.7 \\
\hline $35-49$ & 3488 & 30.6 & 70.9 & 23.0 & 6.1 \\
\hline \multicolumn{6}{|l|}{ Place of residence ${ }^{*}$} \\
\hline Rural & 7649 & 67.1 & 83.8 & 13.5 & 2.6 \\
\hline Urban & 3749 & 32.9 & 73.9 & 20.0 & 6.1 \\
\hline \multicolumn{6}{|l|}{ Municipality of residence ${ }^{*}$} \\
\hline Aileu & 482 & 4.2 & 86.5 & 11.0 & 2.5 \\
\hline Ainaro & 459 & 4.0 & 84.6 & 13.6 & 1.8 \\
\hline Baucau & 1161 & 10.2 & 77.7 & 18.7 & 3.6 \\
\hline Bobonaro & 854 & 7.5 & 86.3 & 10.8 & 2.9 \\
\hline Covalima & 690 & 6.1 & 73.2 & 22.4 & 4.3 \\
\hline Dili & 2856 & 25.1 & 74.1 & 19.7 & 6.2 \\
\hline Ermera & 1090 & 9.6 & 91.4 & 7.5 & 1.2 \\
\hline Lautem & 586 & 5.1 & 83.4 & 14.8 & 1.8 \\
\hline Liquiçá & 670 & 5.9 & 88.3 & 9.9 & 1.8 \\
\hline Manatuto & 491 & 4.3 & 75.5 & 18.3 & 6.3 \\
\hline Manufahi & 628 & 5.5 & 81.6 & 14.6 & 3.7 \\
\hline SAR of Oecussi & 697 & 6.1 & 87.2 & 10.8 & 2.0 \\
\hline Viqueque & 734 & 6.4 & 75.0 & 20.5 & 4.5 \\
\hline
\end{tabular}

Highest educational status*

\begin{tabular}{|c|c|c|c|c|c|}
\hline No formal education & 2480 & 21.8 & 84.7 & 13.2 & 2.1 \\
\hline Primary & 1749 & 15.4 & 77.1 & 18.0 & 4.9 \\
\hline Secondary & 5925 & 52.0 & 80.9 & 15.3 & 3.9 \\
\hline Higher & 1243 & 10.9 & 75.7 & 19.3 & 5.1 \\
\hline \multicolumn{6}{|l|}{ Currently employed* } \\
\hline No & 7497 & 65.8 & 82.4 & 14.3 & 3.3 \\
\hline Yes & 3901 & 34.2 & 77.0 & 18.3 & 4.8 \\
\hline \multicolumn{6}{|l|}{ Household wealth status* } \\
\hline Poorest & 1880 & 16.5 & 88.0 & 10.3 & 1.7 \\
\hline Poorer & 2056 & 18.0 & 86.5 & 11.0 & 2.5 \\
\hline Middle & 2190 & 19.2 & 82.0 & 15.9 & 2.1 \\
\hline Richer & 2512 & 22.0 & 77.4 & 17.5 & 5.1 \\
\hline Richest & 2759 & 24.2 & 72.9 & 20.9 & 6.3 \\
\hline \multicolumn{6}{|l|}{ Marital status* } \\
\hline Single & 4559 & 40.0 & 91.3 & 7.2 & 1.5 \\
\hline Currently married & 5873 & 51.5 & 72.0 & 22.4 & 5.6 \\
\hline Separated/divorced/widowed & 971 & 8.5 & 82.0 & 14.7 & 3.3 \\
\hline \multicolumn{6}{|l|}{ Parity ${ }^{*}$} \\
\hline 0 & 4834 & 42.4 & 90.5 & 7.9 & 1.6 \\
\hline 1 & 1023 & 9.0 & 83.3 & 13.0 & 3.7 \\
\hline 2 & 1109 & 9.7 & 74.6 & 21.4 & 4.0 \\
\hline 3 & 1060 & 9.3 & 70.9 & 23.5 & 5.7 \\
\hline
\end{tabular}

Continued 
Table 1 Continued

\begin{tabular}{|c|c|c|c|c|c|}
\hline \multirow[b]{2}{*}{ Background characteristics } & \multirow[b]{2}{*}{$\mathbf{N}$} & \multirow[b]{2}{*}{$\%$} & \multicolumn{3}{|l|}{ BMI status (\%) } \\
\hline & & & $\mathrm{BMI}<23 \mathrm{~kg} / \mathrm{m}^{2}$ & $23 \mathrm{~kg} / \mathrm{m}^{2} \geq \mathrm{BMI}<27.5 \mathrm{~kg} / \mathrm{m}^{2}$ & $\mathrm{BMI} \geq 27.5 \mathrm{~kg} / \mathrm{m}^{2}$ \\
\hline$>3$ & 3372 & 29.6 & 70.5 & 23.3 & 6.2 \\
\hline \multicolumn{6}{|l|}{ Number of household members } \\
\hline$\leq 6$ & 5960 & 52.3 & 80.8 & 15.9 & 3.3 \\
\hline$>6$ & 5438 & 47.7 & 80.3 & 15.4 & 4.4 \\
\hline \multicolumn{6}{|l|}{ Frequency of viewing television* } \\
\hline Not at all & 4697 & 41.2 & 85.3 & 12.5 & 2.3 \\
\hline Less than once a week & 2376 & 20.8 & 80.0 & 16.2 & 3.8 \\
\hline At least once a week & 4325 & 38.0 & 75.8 & 18.8 & 5.4 \\
\hline
\end{tabular}

Categorical variables were analysed via $\chi^{2}$ test. Asterisks $\left({ }^{*}\right)$ denote level of statistical significance, derived from the $\chi^{2}$ test. ${ }^{*} \mathrm{P}$ value $<0.001$.

BMI, body mass index; $n$, frequency.

obesity was the highest among women aged 35-49 years $(p<0.001)$ and women who belonged to the municipalities of Covalima and Viqueque $(\mathrm{p}<0.001)$. Urban areas had a higher prevalence of overweight and obesity compared with rural areas (overweight: urban $20.0 \%$ vs rural 13.5\%; obesity: urban $6.1 \%$ vs rural $2.6 \%$; p $<0.001$ ). Women whose educational attainment was beyond the secondary level had the highest prevalence of overweight and obesity $(\mathrm{p}<0.001)$. A higher prevalence of overweight and obesity was observed in the higher quintiles of wealth index, with the 'richest' having the highest prevalence of all $(\mathrm{p}<0.001)$. Furthermore, married women had a higher prevalence than unmarried ones $(\mathrm{p}<0.0001)$. Women who watched TV at least once a week had a higher prevalence of overweight and obesity than other groups $(\mathrm{p}<0.0001)$ (table 1$)$.

\section{Correlates of overweight and obesity}

In the ordered logistic regression model, the normal and underweight category (BMI $<23 \mathrm{~kg} / \mathrm{m}^{2}$ ) was held as the reference group, while the possible correlates of overweight or obesity were identified based on COR and AOR calculations (table 2). After controlling for the covariates, age, type of settlement, municipality, educational attainment, wealth and marital status, and frequency of TV viewing were all found to be the statistically significant correlates of overweight or obesity. On the contrary, household size, employment status and parity did not show any statistically significant relationship with TV viewing frequency.

The difference between urban and rural women in terms of TV viewing frequency is illustrated in figure 1 (see online supplemental file 1). The proportion of respondents who watched TV at least once a week was significantly higher in urban areas compared with rural areas (urban: $64.1 \%$ vs rural: $39.5 \%, \mathrm{p}<0.0001$ ).

\section{Relationship between frequency of watching TV and overweight and obesity after stratification by type of settlement}

Overall, women who watched TV at least once a week had 1.3 times the odds of being overweight or obese compared with women who never watched TV (AOR: $1.3,95 \%$ CI: 1.1 to $1.5 ; \mathrm{p}<0.001$ ). (table 2 ). After stratification by type of settlement (urban/rural) (table 3 ) and adjustment for other covariates (eg, age, municipality of residence, the status of wealth and employment, educational and marital status, parity and household size) that were found to have a statistically significant association with overweight and obesity in bivariate analyses $(\mathrm{p}<0.05)$, it was found that rural women who watched TV at least once a week had higher odds of being overweight or obese than those who did not watch TV at all (AOR: 1.5, 95\% CI: 1.2 to 1.8; $\mathrm{p}<0.001)$. Conversely, no significant association between overweight and obesity and the frequency of watching TV was observed among urban women (table 3 ). The logistic regression results found in the urban and rural strata, separately, are presented in online supplemental tables 2 and 3 .

Similar estimates were generated while comparing the odds of overweight and obesity while keeping normal BMI as a reference category (table 4 ). The detailed models are shown in online supplemental tables 4-6.

Linear regression also revealed an increase in BMI as the frequency of watching TV increases. However, stratification yielded significant result only in rural areas (table 5). The detailed models are shown in online supplemental tables 7-9.

Watching TV at least once a week was associated with $10 \%$ lower odds of underweight compared with not watching TV at all (online supplemental table 10).

\section{DISCUSSION}

To the best of our knowledge, this is the first-ever study on Timor-Leste that analysed a nationally representative DHS dataset to investigate the association between frequency of TV watching and overweight and obesity among women of reproductive age. The data from a weighted sample of 11398 Timorese women revealed a statistically significant association between frequency of 
Table 2 Crude and adjusted ORs for factors associated with overweight and obesity $\left(\mathrm{BMI} \geq 27.5 \mathrm{~kg} / \mathrm{m}^{2}\right)$, compared with normal BMl or underweight $\left(\mathrm{BMl}<23 \mathrm{~kg} / \mathrm{m}^{2}\right)$ among Timorese women of reproductive age

\begin{tabular}{|c|c|c|c|c|c|c|}
\hline \multirow[b]{2}{*}{ Background characteristics } & \multirow[b]{2}{*}{ COR } & \multicolumn{2}{|l|}{$95 \% \mathrm{Cl}$} & \multirow[b]{2}{*}{ AOR } & \multicolumn{2}{|l|}{$95 \% \mathrm{Cl}$} \\
\hline & & Lower limit & Upper limit & & Lower limit & Upper limit \\
\hline \multicolumn{7}{|l|}{ Age group (years) } \\
\hline $15-24$ & Ref & & & Ref & & \\
\hline $25-34$ & $3.7^{*}$ & 3.2 & 4.2 & $1.9^{*}$ & 1.6 & 2.3 \\
\hline $35-49$ & $5.0^{*}$ & 4.4 & 5.7 & $2.3^{*}$ & 1.9 & 2.9 \\
\hline \multicolumn{7}{|l|}{ Place of residence } \\
\hline Rural & Ref & & & Ref & & \\
\hline Urban & $1.8^{*}$ & 1.6 & 2.1 & $1.4^{*}$ & 1.2 & 1.6 \\
\hline
\end{tabular}

Province of residence

\begin{tabular}{|c|c|c|c|c|c|c|}
\hline Aileu & Ref & & & Ref & & \\
\hline Ainaro & 1.3 & 0.9 & 1.8 & 1.2 & 0.9 & 1.7 \\
\hline Baucau & $1.8^{*}$ & 1.3 & 2.5 & $1.5 \ddagger$ & 1.1 & 2.0 \\
\hline Bobonaro & 1.1 & 0.8 & 1.5 & 0.9 & 0.6 & 1.2 \\
\hline Covalima & $2.1^{*}$ & 1.5 & 2.9 & $1.7 \dagger$ & 1.3 & 2.3 \\
\hline Dili & $2.2^{*}$ & 1.6 & 2.9 & 1.2 & 0.9 & 1.7 \\
\hline Ermera & 0.7 & 0.5 & 1.0 & 0.7 & 0.5 & 1.0 \\
\hline Lautem & 1.3 & 1.0 & 1.9 & 1.0 & 0.7 & 1.4 \\
\hline Liquiçá & 0.9 & 0.6 & 1.2 & 0.8 & 0.6 & 1.2 \\
\hline Manatuto & $2.1^{*}$ & 1.5 & 2.9 & $1.6+$ & 1.2 & 2.2 \\
\hline Manufahi & $1.5 \ddagger$ & 1.1 & 2.1 & 1.3 & 0.9 & 1.7 \\
\hline SAR of Oecussi & 1.0 & 0.7 & 1.5 & 0.8 & 0.5 & 1.1 \\
\hline Viqueque & $2.0^{\star}$ & 1.5 & 2.8 & $1.8^{*}$ & 1.3 & 2.5 \\
\hline \multicolumn{7}{|l|}{ Highest educational status } \\
\hline No formal education & Ref & & & Ref & & \\
\hline Primary & $1.6^{\star}$ & 1.4 & 1.9 & $1.7^{\star}$ & 1.4 & 2.0 \\
\hline Secondary & 1.1 & 1.0 & 1.3 & $1.5^{\star}$ & 1.3 & 1.8 \\
\hline Higher & $1.4 \dagger$ & 1.2 & 1.7 & $1.4 \dagger$ & 1.1 & 1.8 \\
\hline \multicolumn{7}{|l|}{ Currently employed } \\
\hline No & Ref & & & Ref & & \\
\hline Yes & $1.6^{\star}$ & 1.5 & 1.8 & 1.1 & 1.0 & 1.2 \\
\hline \multicolumn{7}{|l|}{ Household Wealth index } \\
\hline Poorest & Ref & & & Ref & & \\
\hline Poorer & 1.1 & 0.9 & 1.4 & 1.1 & 0.9 & 1.4 \\
\hline Middle & $1.5^{\star}$ & 1.2 & 1.8 & $1.3 \dagger$ & 1.1 & 1.6 \\
\hline Richer & $2.1^{*}$ & 1.7 & 2.5 & $1.6^{\star}$ & 1.3 & 2.0 \\
\hline Richest & $2.7^{*}$ & 2.2 & 3.2 & $1.9^{*}$ & 1.5 & 2.4 \\
\hline \multicolumn{7}{|l|}{ Marital status } \\
\hline Single & Ref & & & Ref & & \\
\hline Currently married & $4.7^{*}$ & 4.1 & 5.3 & $2.9^{\star}$ & 2.2 & 3.8 \\
\hline Separated/divorced/widowed & $2.9^{*}$ & 2.3 & 3.5 & $2.2^{*}$ & 1.6 & 3.0 \\
\hline \multicolumn{7}{|l|}{ Parity } \\
\hline 0 & Ref & & & Ref & & \\
\hline 1 & $1.9^{*}$ & 1.5 & 2.3 & $0.6 \dagger$ & 0.5 & 0.8 \\
\hline 2 & $3.1^{*}$ & 2.6 & 3.7 & 0.9 & 0.7 & 1.2 \\
\hline
\end{tabular}


Table 2 Continued

\begin{tabular}{|c|c|c|c|c|c|c|}
\hline \multirow[b]{2}{*}{ Background characteristics } & \multirow[b]{2}{*}{ COR } & \multicolumn{2}{|l|}{$95 \% \mathrm{Cl}$} & \multirow[b]{2}{*}{ AOR } & \multicolumn{2}{|l|}{$95 \% \mathrm{Cl}$} \\
\hline & & Lower limit & Upper limit & & Lower limit & Upper limit \\
\hline 3 & $4.5^{\star}$ & 3.8 & 5.3 & 1.1 & 0.8 & 1.5 \\
\hline \multicolumn{7}{|l|}{ Number of household member } \\
\hline$\leq 6$ & Ref & & & Ref & & \\
\hline \multicolumn{7}{|l|}{ Frequency of viewing television } \\
\hline Not at all & Ref & & & Ref & & \\
\hline Less than once a week & $1.5^{\star}$ & 1.3 & 1.7 & $1.2 \ddagger$ & 1.0 & 1.4 \\
\hline At least once a week & $1.7^{*}$ & 1.5 & 1.9 & $1.3^{\star}$ & 1.1 & 1.5 \\
\hline
\end{tabular}

Results are based on ordered logistic regression. Asterisks $\left(^{*}\right)$ denote level of statistical significance.

${ }^{*} \mathrm{P}$ value $<0.001$.

†P value $<0.01$

$\ddagger P$ value $<0.05$.

AOR, adjusted odds ratio; BMI, body mass index; COR, crude odds ratio.

TV viewing and being overweight or obese. However, when stratified by the type of settlement (urban/rural), the statistical significance stood only for the Timorese women belonging to the rural stratum.

The prevalence of overweight and obesity using Asian criteria-based BMI cut-offs (BMI $\geq 23 \mathrm{~kg} / \mathrm{m}^{2}$ ) among the Timorese women of reproductive age was found to be $19.4 \%$, which is lower than that of the neighbouring Southeast Asian countries: Vietnam, ${ }^{47}$ Cambodia, ${ }^{48}$ Malaysia, ${ }^{49}$ Laos $^{50}$ and Thailand ${ }^{51}$ Given that Timor-Leste is arguably the least developed country in this region, ${ }^{22}$ the comparatively lower proportion of underweight or obesity is understandable. Despite going through epidemiological transitions, undernourishment is still the bigger problem among Timorese women of reproductive age ${ }^{23}$ However, the methodological contrasts among studies of different Southeast Asian countries (eg, BMI cut-offs, study population, and sampling and measurement techniques) may limit direct comparison. In terms of the correlates; however, higher age groups, ${ }^{47} 50$ higher

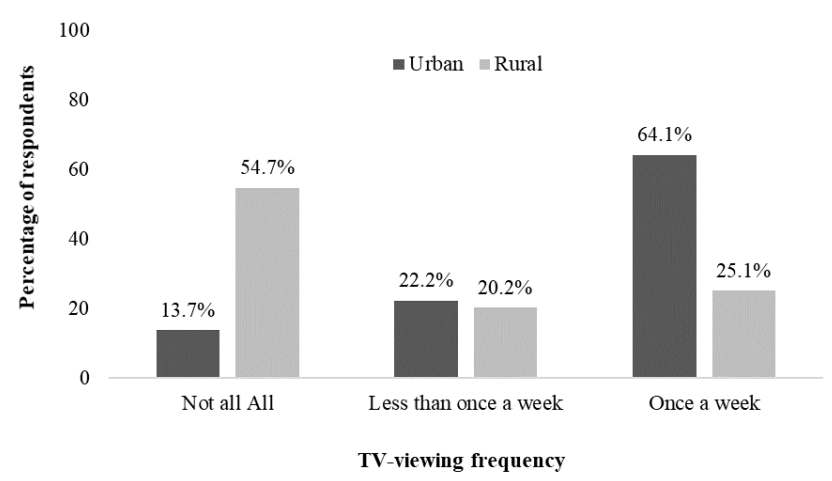

Figure 1 Percentage of sample $(n=11398)$ in urban and rural areas across three categories of TV viewing frequency. wealth status ${ }^{47}$ and urban settlement ${ }^{50} 52$ were previously found to have significantly higher odds of overweight or obesity, which is consistent with the present study results.

The present study found a positive and statistically significant association between frequency of TV viewing and being overweight or obese among women of reproductive age. A number of studies over the years, conducted on people of different age groups, have established a similar positive association between the two in Western ${ }^{53-56}$ as well as Eastern settings. ${ }^{57-60}$ This observed positive association can be explained through at least two possible mechanisms. First, TV watching time may replace the time that could have been used for exercise or discretionary physical activities; this may result in a reduction in overall energy expenditure and subsequently lead to weight gain. ${ }^{5561}$ Decreased energy expenditure and its consequent increase in sedentariness were found to have detrimental metabolic repercussions on adults irrespective of their meeting the recommended physical activity guidelines, posing negative implications on their BMI status. ${ }^{62}$ In particular, people in developing countries are reportedly shifting from an active lifestyle towards sedentariness due to greater access to mechanical appliances, TV being one of them. ${ }^{63}$ Being a developing country itself, Timor-Leste might not be an exception to such a shift, and Timorese women may be resorting to TV viewing as their primary form of recreation rather than engaging in physically demanding recreational or outdoor activities. Second, TV viewing time is also hypothesised to result in increased energy intake. ${ }^{24} 275561$ Watching TV was found to be associated with the urge to consume more savoury snacks and high-calorie drinks. ${ }^{64} 65$ These unhealthy dietary practices, while watching TV, are hypothesised to be related to abdominal obesity in women. ${ }^{55}$ One of the factors that might drive this tendency is the abundance of TV programmes with commercials or advertisements 
Table 3 Association between frequency of watching TV and overweight and obesity (after stratification by type of settlement) among women of reproductive age in Timor-Leste

\begin{tabular}{|c|c|c|}
\hline Frequency of watching television & COR (95\% Cl) & AOR $(95 \% \mathrm{Cl})$ \\
\hline \multicolumn{3}{|l|}{ Urban areas } \\
\hline Not at all & Reference & Reference \\
\hline Less than once a week & $1.3^{*}(1.0$ to 1.6$)$ & 1.1 (0.8 to 1.4$)$ \\
\hline At least once a week & $1.3^{\star}(1.0$ to 1.6$)$ & 1.1 (0.8 to 1.4$)$ \\
\hline \multicolumn{3}{|l|}{ Rural areas } \\
\hline Not at all & Reference & Reference \\
\hline Less than once a week & $1.3 \dagger(1.1$ to 1.6$)$ & $1.3 \dagger(1.0$ to 1.5$)$ \\
\hline At least once a week & $1.7^{\star}(1.5$ to 2.0$)$ & $1.5^{\star}(1.2$ to 1.8$)$ \\
\hline \multicolumn{3}{|l|}{ Overall } \\
\hline Not at all & Reference & Reference \\
\hline Less than once a week & $1.5^{\star}(1.3$ to 1.7$)$ & $1.2 \ddagger(1.0$ to 1.4$)$ \\
\hline At least once a week & $1.7^{\star}(1.5$ to 1.9$)$ & $1.3^{*}(1.1$ to 1.5$)$ \\
\hline
\end{tabular}

Results are based on ordered logistic regression and adjusted for age, place of residence, municipality of residence, highest educational status, current employment and marital status, Wealth index, parity and number of household members; women having BMl $<23 \mathrm{~kg} / \mathrm{m}^{2}$ were held as the reference group. Asterisks $\left.{ }^{*}\right)$ denote level of statistical significance.

${ }^{*} \mathrm{P}$ value $<0.001$

$\dagger P$ value $<0.01$

$\ddagger P$ value $<0.05$.

AOR, adjusted odds ratio; COR, crude odds ratio.

for energy-dense foods, ${ }^{66} 67$ which may determine dietary choices in other parts of the day. ${ }^{68} \mathrm{~A}$ content analysis study on selected Nepali and Indian TV channels found roughly $25 \%$ of broadcasted commercials to be promoting preprepared or packaged food with low nutritional value. ${ }^{69}$ Besides, these commercials are more likely to reach the ones spending a considerable amount of time in front of the TV and entice them through attractive communication techniques to purchase and consume obesogenic food products, which, in combination with

Table 4 Association between frequency of watching TV and overweight and obesity (after stratification by type of settlement) among women of reproductive age in Timor-Leste, compared with normal BMI

\begin{tabular}{|c|c|c|}
\hline Frequency of watching television & COR $(95 \% \mathrm{Cl})$ & AOR $(95 \% \mathrm{Cl})$ \\
\hline \multicolumn{3}{|l|}{ Urban areas } \\
\hline Not at all & Reference & Reference \\
\hline At least once a week & $1.2 \ddagger(1.0$ to 1.5$)$ & 1.0 (0.7 to 1.2$)$ \\
\hline \multicolumn{3}{|l|}{ Rural areas } \\
\hline Less than once a week & $1.4 \dagger(1.2$ to 1.7$)$ & $1.2 \ddagger(1.0$ to 1.5$)$ \\
\hline At least once a week & $1.7^{\star}(1.4$ to 2.0$)$ & $1.4 \dagger(1.2$ to 1.7$)$ \\
\hline \multicolumn{3}{|l|}{ Overall } \\
\hline Not at all & Reference & Reference \\
\hline Less than once a week & $1.5^{\star}(1.3$ to 1.7$)$ & $1.2 \ddagger(1.0$ to 1.4$)$ \\
\hline
\end{tabular}

Results are based on ordered logistic regression and adjusted for age, place of residence, municipality of residence, highest educational status, current employment and marital status, wealth index, parity, and number of household members; women having BMI $18.5-23 \mathrm{~kg} / \mathrm{m}^{2}$ were held as the reference group. Asterisks $\left({ }^{*}\right)$ denote level of statistical significance.

${ }^{*} P$ value $<0.001$

$\dagger P$ value $<0.01$

$\ddagger \mathrm{P}$ value $<0.05$.

AOR, adjusted odds ratio; BMI, body mass index; COR, crude odds ratio. 
Table 5 Association between frequency of watching TV and BMI (after stratification by type of settlement) among women of reproductive age in Timor-Leste

\begin{tabular}{|c|c|c|}
\hline Frequency of watching television & Crude beta-coefficient $(95 \% \mathrm{Cl})$ & Adjusted beta-coefficient $(95 \% \mathrm{Cl})$ \\
\hline \multicolumn{3}{|l|}{ Urban areas } \\
\hline Not at all & Reference & Reference \\
\hline At least once a week & $0.45 \ddagger(0.13$ to 0.76$)$ & $0.29(-0.04$ to 0.61$)$ \\
\hline \multicolumn{3}{|l|}{ Rural areas } \\
\hline At least once a week & $0.60^{*}(0.39$ to 0.80$)$ & $0.43^{*}(0.19$ to 0.67$)$ \\
\hline \multicolumn{3}{|l|}{ Overall } \\
\hline Not at all & Reference & Reference \\
\hline Less than once a week & $0.42^{*}(0.24$ to 0.60$)$ & $0.27 \ddagger(0.08$ to 0.46$)$ \\
\hline
\end{tabular}

Results are based on linear regression and adjusted for age, place of residence, municipality of residence, highest educational status, current employment and marital status, wealth index, parity, and number of household members. Asterisks $\left(^{*}\right)$ denote level of statistical significance. ${ }^{*} \mathrm{P}$ value $<0.001$

$\dagger P$ value $<0.01$

$\ddagger \mathrm{P}$ value $<0.05$

$\mathrm{BMI}$, body mass index.

their sedentary behaviour, make them prone to being overweight and obese. ${ }^{25}$

Nevertheless, after stratification of TV viewing status based on settlement type (urban/rural), the statistical significance of its relationship with BMI held up only in the rural stratum. Conversely, in the urban stratum, although watching TV 'at least one a week' gave one higher odds of being overweight or obese, it lacked statistical significance, which contrasts prior studies on this aspect. ${ }^{40}$ This apparent contradiction may be explained from two different angles. First, the statistical significance found in the rural stratum could be because the ongoing epidemiological and demographic transitions and gradual increase in gross national income in the underdeveloped and developing countries may be resulting in gradual, yet meaningful diffusion of urban behavioural risk factors to rural areas, such as the adoption of a sedentary lifestyle, increased screen time, consumption of obesogenic food and greater reliance on the mechanised systems for routine chores and transportation. ${ }^{27} 70$ Second, the relationship lacked statistical significance in the urban stratum possibly because of other unknown behavioural practices that might have confounded the relationship. The ability of this study to assess the relationship was constrained by the fact that frequency of TV watching was the only available measure of screen time and due to the lack of data, our study could not control for other potential confounders or mediators (eg, dietary habit, physical activity, screen time other than TV watching) of the relationship between TV viewing and overweight or obesity in urban areas.

Much as this study provides useful insights on the potential correlates of overweight and obesity and the possible mechanism of its relationship with TV viewing frequency, it also highlights the need to interpret its finding cautiously in light of potential limitations. First, the cross-sectional nature of this study prevents us from drawing causal conclusions about the hypothesised relationship between TV viewing and overweight and obesity. Nonetheless, this hypothesis was previously tested in prospective cohort studies that found temporal relationships between frequency of TV watching and incidence of overweight or obesity ${ }^{25} 71$ as well as in an experimental study that found moderation of the TV viewing time to have a protective association with $\mathrm{BMI},{ }^{72}$ suggesting that reverse causation would be unlikely. Second, a self-reported measurement of TV viewing frequency/ duration may have led to a reporting bias. Third, due to the lack of data, some of the potentially important behavioural risk factors of BMI (eg, inactivity or sedentary status, poor dietary habit, tobacco and alcohol consumption) could not be adjusted to discern the strength of the independent relationship between TV viewing and overweight and obesity. Moreover, a more precise duration of TV viewing and the nature of the media content that Timorese women are exposed to may need to be looked at in future studies. ${ }^{27}$

Notwithstanding the aforementioned limitations, this study is the first one to assess the relationship of TV viewing frequency with overweight and obesity in Timor-Leste, where the prevalence of overnutrition is on the rise due to ongoing epidemiological transition. Moreover, this study analysed a nationally representative survey dataset with a high response rate $(97 \%)$, hence the findings are generalisable to a great extent. Moreover, the TLDHS 2016 utilised validated questionnaires, calibrated measurement tools and well-trained enumerators and technicians, limiting the chance of measurement error. Furthermore, this study contributes to generating representative prevalence estimates of BMI categories and their cross-sectionally associated factors among Timorese women of reproductive age, 
thereby helping to widen the knowledge of some of the potential drivers of malnutrition in this context.

\section{CONCLUSION}

The ongoing epidemiological transition in Timor-Leste makes this country susceptible to a forthcoming dual burden of malnutrition. Compared with other groups, the Timorese women of reproductive age are more prone to suffer from complications of overweight and obesity due to their additional gestational and obstetric issues. This study demonstrates TV viewing frequency to be a statistically significant correlate of overweight and obesity among that age group. Therefore, intervention planners should incorporate behavioural change communication messages regarding dietary and physical activity reforms in the existing TV programmes to leverage TV viewing time, if not advice for replacing the screen time with physically demanding discretionary activities.

\section{Author affiliations}

${ }^{1}$ BRAC James P Grant School of Public Health, BRAC University, Dhaka, Bangladesh ${ }^{2}$ Department of Epidemiology and Biostatistics, Arnold School of Public Health,

University of South Carolina, Columbia, South Carolina, USA

${ }^{3}$ Bangladesh Civil Service, Ministry of Health and Family Welfare, Dhaka,

Bangladesh

${ }^{4}$ Department of Mathematical Sciences, School of Natural Sciences \& Mathematics, University of Texas at Dallas, Dallas, Texas, USA

${ }^{5}$ Heidelberg Institute of Global Health, Heidelberg University, Heidelberg, Germany

\section{Twitter Rajat Das Gupta @rajatdasgupta11}

Contributors AT, RDG and MS conceptualised the study. AT, RDG, MRH and MS designed the study and acquired the data. AT, RDG and IHS conducted the data analysis. AT, RDG, MRH, SSH, IHS and MS interpreted the data. AT, RDG, MRH and SSH prepared the first draft. AT, RDG, MRH, SSH, IHS and MS participated in critical revision of the manuscript and contributed to its intellectual improvement. All authors went through the final draft and approved it for submission.

Funding The authors have not declared a specific grant for this research from any funding agency in the public, commercial or not-for-profit sectors.

Competing interests None declared.

Patient consent for publication Not required.

Ethics approval The ICF Institutional Review Board reviewed and approved the study protocol of the TLDHS 2016. Informed written consent was taken from the respondents before data collection. Permission for using the dataset was obtained from the DHS programme in May 2020.

Provenance and peer review Not commissioned; externally peer reviewed.

Data availability statement Data are available upon reasonable request. The dataset of TLDHS 2016 is available on the DHS website and can be accessed upon request.

Supplemental material This content has been supplied by the author(s). It has not been vetted by BMJ Publishing Group Limited (BMJ) and may not have been peer-reviewed. Any opinions or recommendations discussed are solely those of the author(s) and are not endorsed by BMJ. BMJ disclaims all liability and responsibility arising from any reliance placed on the content. Where the content includes any translated material, BMJ does not warrant the accuracy and reliability of the translations (including but not limited to local regulations, clinical guidelines, terminology, drug names and drug dosages), and is not responsible for any error and/or omissions arising from translation and adaptation or otherwise.

Open access This is an open access article distributed in accordance with the Creative Commons Attribution Non Commercial (CC BY-NC 4.0) license, which permits others to distribute, remix, adapt, build upon this work non-commercially, and license their derivative works on different terms, provided the original work is properly cited, appropriate credit is given, any changes made indicated, and the use is non-commercial. See: http://creativecommons.org/licenses/by-nc/4.0/.

\section{ORCID iDs}

Animesh Talukder http://orcid.org/0000-0003-4174-3903

Rajat Das Gupta http://orcid.org/0000-0002-7680-676X

Mohammad Rashidul Hashan http://orcid.org/0000-0002-1627-4976

\section{REFERENCES}

1 Stanaway JD, Afshin A, Gakidou E, et al. Global, regional, and national comparative risk assessment of 84 behavioural, environmental and occupational, and metabolic risks or clusters of risks for 195 countries and territories, 1990-2017: a systematic analysis for the global burden of disease study 2017. The Lancet 2018;392:1923-94.

2 Wormser D, Kaptoge S, Di Angelantonio E. Separate and combined associations of body-mass index and abdominal adiposity with cardiovascular disease: collaborative analysis of 58 prospective studies. The Lancet 2011;377:1085-95.

3 Singh GM, Danaei G, Farzadfar F, et al. The age-specific quantitative effects of metabolic risk factors on cardiovascular diseases and diabetes: a pooled analysis. PLoS One 2013;8:e65174.

4 Lauby-Secretan B, Scoccianti C, Loomis D, et al. Body fatness and cancer - viewpoint of the IARC Working group. New England Journal of Medicine 2016;375:794-8.

5 Jiang L, Rong J, Wang Y, et al. The relationship between body mass index and hip osteoarthritis: a systematic review and meta-analysis. Joint Bone Spine 2011;78:150-5.

6 Jiang L, Tian W, Wang Y, et al. Body mass index and susceptibility to knee osteoarthritis: a systematic review and meta-analysis. Joint Bone Spine 2012;79:291-7.

7 Guh DP, Zhang W, Bansback N, et al. The incidence of comorbidities related to obesity and overweight: a systematic review and meta-analysis. BMC Public Health 2009;9:88.

8 Sattar N, Mclnnes IB, McMurray JJV. Obesity is a risk factor for severe COVID-19 infection: multiple potential mechanisms. Circulation 2020;142:4-6.

9 Simonnet A, Chetboun M, Poissy J, et al. High prevalence of obesity in severe acute respiratory syndrome coronavirus-2 (SARS-CoV-2) requiring invasive mechanical ventilation. Obesity 2020;28:1195-9.

10 Simonnet A, Chetboun M, Poissy J, et al. High prevalence of obesity in severe acute respiratory syndrome Coronavirus-2 (SARS-CoV-2) requiring invasive mechanical ventilation. Obesity 2020;28:1195-9.

11 Kass DA, Duggal P, Cingolani O. Obesity could shift severe COVID-19 disease to younger ages. The Lancet 2020;395:1544-5.

12 Ofei F. Obesity - a preventable disease. Ghana Med J 2005;39:98-101.

13 Williamson DA, Jack Rejeski W. Obesity and health- related quality of life. in: Handbook of obesity: epidemiology, etiology, and physiopathology, third edition. Boca Raton: CRC Press, 2014: 645-55.

14 Peeters A, Barendregt JJ, Willekens F, et al. Obesity in adulthood and its consequences for life expectancy: a life-table analysis. Ann Intern Med 2003;138:24-32.

15 Withrow D, Alter DA. The economic burden of obesity worldwide: a systematic review of the direct costs of obesity. Obes Rev 2011;12:131-41.

16 Ng M, Fleming T, Robinson M, et al. Global, regional, and national prevalence of overweight and obesity in children and adults during 1980-2013: a systematic analysis for the global burden of disease study 2013. Lancet 2014;384:766-81.

17 Cefalu WT, Bray GA, Home PD, et al. Advances in the science, treatment, and prevention of the disease of obesity: reflections from a diabetes care editors' expert forum. Diabetes Care 2015;38:1567-82.

18 Kanguru L, McCaw-Binns A, Bell J, et al. The burden of obesity in women of reproductive age and in pregnancy in a middle-income setting: a population based study from Jamaica. PLOS One 2017;12:e0188677.

19 Stupin J, Arabin B. Overweight and obesity before, during and after pregnancy. Geburtshilfe Frauenheilkd 2014;74:639-45.

20 Hanson M, Gluckman P, Bustreo F. Obesity and the health of future generations. Lancet Diabetes Endocrinol 2016;4:966-7.

21 CIA. Central Intelligence Agency - The World Factbook - Timor-Leste. CIA Library. 2012;000:5-8, 2012. Available: https://www.cia.gov/theworld-factbook/countries/timor-leste/

22 United Nations. LDCs at a glance | department of economic and social affairs. United nations department of economic and social 
Affairs, 2018. Available: https://www.un.org/development/desa/dpad/ least-developed-country-category/ldcs-at-a-glance.html

23 Global Nutrition Report. Timor-Leste nutrition profile - Global Nutrition Report, 2020. Available: https://globalnutritionreport.org/ resources/nutrition-profiles/asia/south-eastern-asia/timor-leste/

24 FB H, TY L, Colditz GA. Television watching and other sedentary behaviors in relation to risk of obesity and type 2 diabetes mellitus in women. J Am Med Assoc 2003;289:1785-91.

25 Chen C-Y, Pereira MA, Kim KH, et al. Fifteen-Year prospective analysis of television viewing and adiposity in African American and Caucasian men and women. SAGE Open 2015;5:215824401560048.

26 Robinson TN. Reducing children's television viewing to prevent obesity: a randomized controlled trial. JAMA 1999;282:1561-7.

27 Tuoyire DA. Television exposure and overweight/obesity among women in Ghana. BMC Obes 2018;5.

28 Wojtyła A, Kapka-Skrzypczak L, Biliński P. Physical activity among women at reproductive age and during pregnancy (Youth Behavioural Polish Survey - YBPS and pregnancy-related assessment monitoring survay - PrAMS) - epidemiological population studies in Poland during the period 2010-2011. Annals of Agricultural and Environmental Medicine 2011;18:365-74.

29 Foucaut A-M, Faure C, Julia C, et al. Sedentary behavior, physical inactivity and body composition in relation to idiopathic infertility among men and women. PLoS One 2019;14:e0210770.

30 Oddo VM, Maehara M, Rah JH. Overweight in Indonesia: an observational study of trends and risk factors among adults and children. BMJ Open 2019;9:e031198.

31 Sarma H, Saquib N, Hasan MM, et al. Determinants of overweight or obesity among ever-married adult women in Bangladesh. BMC Obes 2016;3:13.

32 Biswas T, Uddin MJ, Mamun AA, Al MA, et al. Increasing prevalence of overweight and obesity in Bangladeshi women of reproductive age: findings from 2004 to 2014. PLoS One 2017;12:e0181080.

33 Guinness L, Paul RC, Martins JS, et al. Determinants of health care utilisation: the case of Timor-Leste. Int Health 2018;10:412-20.

34 The World Bank. World bank open data. data catalog. 20164;:1, 2016. Available: https://data.worldbank.org/

35 Ministry of Finance. Timor-Leste strategic development plan 2011-30. DILI, Timor-Leste 2011.

36 Hou X, Witter S, Zaman RU, et al. What do health workers in TimorLeste want, know and do? findings from a national health labour market survey. Hum Resour Health 2016;14:69.

37 Hou X, Asante AD. Turning challenges into opportunities: the medium term health expenditure pressure study in Timor-Leste 2016.

38 General Directorate of Statistics. Timor-Leste demographic and health survey 2016, 2018. Available: https://dhsprogram.com/ publications/publication-fr329-dhs-final-reports.cfm

39 WHO Expert Consultation. Appropriate body-mass index for Asian populations and its implications for policy and intervention strategies. Lancet 2004;363:157-63.

40 Ghose B. Frequency of TV viewing and prevalence of overweight and obesity among adult women in Bangladesh: a cross-sectional study. BMJ Open 2017;7:e014399.

41 Jolliffe IT, Cadima J. Principal component analysis: a review and recent developments. Philos Trans A Math Phys Eng Sci 2016;374:20150202.

42 Hox JJ. Multilevel analysis: techniques and applications. Second edition. Milton: Routledge, 2010.

43 Oyen $\mathrm{H}$. Multilevel analysis of survey data. International Journal of Public Health 2009;54:129-30.

44 Goldstein H. Multilevel statistical models. Hoboken: John Wiley \& Sons, 1987.

45 Kutner MH, Nachtsheim CJ, Neter J. Applied linear statistical models fifth edition. New York: McGraw-Hill/Irwin, 2005. www.mhhe.com

46 von Elm E, Altman DG, Egger M, et al. The strengthening the reporting of observational studies in epidemiology (STROBE) statement: guidelines for reporting observational studies. J Clin Epidemiol 2008;61:344-9.

47 Trinh OTH, Nguyen ND, Phongsavan P, et al. Prevalence and risk factors with overweight and obesity among Vietnamese adults: Caucasian and Asian cut-offs. Asia Pac J Clin Nutr 2009;18:226-33.

48 An Y, Yi S, Fitzpatrick A, et al. Appropriate body mass index and waist circumference cutoff for overweight and central obesity among adults in Cambodia. PLoS One 2013;8:e77897.

49 Chan YY, Lim KK, Lim KH, et al. Physical activity and overweight/obesity among Malaysian adults: findings from the 2015 National health and morbidity survey (NHMS). BMC Public Health 2017;17:733.
50 Pengpid S, Vonglokham M, Kounnavong S, et al. The prevalence of underweight and overweight/obesity and its correlates among adults in Laos: a cross-sectional national population-based survey, 2013. Eat Weight Disord 2020;25:265-73.

51 Jitnarin N, Kosulwat V, Rojroongwasinkul N, et al. Prevalence of overweight and obesity in Thai population: results of the National Thai food consumption survey. Eat Weight Disord 2011;16:e242-9.

52 Angkurawaranon C, Jiraporncharoen W, Chenthanakij B, et al. Urban environments and obesity in Southeast Asia: a systematic review, meta-analysis and meta-regression. PLoS One 2014;9:e113547.

53 Andersen RE, Crespo CJ, Bartlett SJ. Relationship of physical activity and television watching with body weight and level of fatness among children results from the third National health and nutrition examination survey. J Am Med Assoc 1998;279:938-42.

54 Tucker LA, Bagwell M. Television viewing and obesity in adult females. Am J Public Health 1991;81:908-11.

55 Cleland VJ, Schmidt MD, Dwyer T, et al. Television viewing and abdominal obesity in young adults: is the association mediated by food and beverage consumption during viewing time or reduced leisure-time physical activity? Am J Clin Nutr 2008;87:1148-55.

56 Braithwaite I, Stewart AW, Hancox RJ, et al. The worldwide association between television viewing and obesity in children and adolescents: cross sectional study. PLoS One 2013;8:e74263.

57 Ghavamzadeh S, Khalkhali HR, Alizadeh M. Tv viewing, independent of physical activity and obesogenic foods, increases overweight and obesity in adolescents. J Health Popul Nutr 2013;31:334-42.

$58 \mathrm{Xu} \mathrm{F}, \mathrm{Li} \mathrm{J}$, Ware RS, et al. Associations of television viewing time with excess body weight among urban and rural high-school students in regional mainland China. Public Health Nutr 2008;11:891-6.

59 Das Gupta R, Sajal IH, Hasan M, et al. Frequency of television viewing and association with overweight and obesity among women of the reproductive age group in Myanmar: results from a nationwide cross-sectional survey. BMJ Open 2019;9:24680.

60 Das GR, Haider SS, Sutradhar I. Association of frequency of television watching with overweight and obesity among women of reproductive age in India: evidence from a nationally representative study. PLOS ONE 2019;14.

61 Maher C, Olds TS, Eisenmann JC, et al. Screen time is more strongly associated than physical activity with overweight and obesity in 9- to 16-year-old Australians. Acta Paediatr 2012;101:1170-4.

62 Hamilton MT, Healy GN, Dunstan DW, et al. Too little exercise and too much sitting: inactivity physiology and the need for new recommendations on sedentary behavior. Curr Cardiovasc Risk Rep 2008;2:292-8.

$63 \mathrm{Ng} \mathrm{SW}$, Popkin BM. Time use and physical activity: a shift away from movement across the globe. Obes Rev 2012;13:659-80.

64 Salmon J, Campbell KJ, Crawford DA. Television viewing habits associated with obesity risk factors: a survey of Melbourne schoolchildren. Medical Journal of Australia 2006;184:64-7.

65 Blass E, Anderson D, Kirkorian H, et al. On the road to obesity: television viewing increases intake of high-density foods. Physiol Behav 2006;88:597-604.

66 Strasburger VC, Mulligan DA, Altmann TR. Policy statement - Children, adolescents, obesity, and the media. Pediatrics 2011;128:201-8.

67 Neville L, Thomas M, Bauman A. Food advertising on Australian television: the extent of children's exposure. Health Promot Int 2005;20:105-12.

68 Borzekowski DL, Robinson TN. The 30-second effect: an experiment revealing the impact of television commercials on food preferences of preschoolers. J Am Diet Assoc 2001;101:42-6.

69 Resource Centre for Primary Health Care (RECPHEC). Rapid assessment on media coverage of junk food and its content analysis on selected Nepali and Indian television channels, 2020. Available: www.recphec.org.np

70 Mendez MA, Monteiro CA, Popkin BM. Overweight exceeds underweight among women in most developing countries. The American Journal of Clinical Nutrition 2005;81:714-21.

71 Dietz WH, Gortmaker SL. Do we fatten our children at the television set? obesity and television viewing in children and adolescents. Pediatrics 1985;75:807-12.

72 Robinson TN. Reducing children's television viewing to prevent obesity: A randomized controlled trial. J Am Med Assoc 1999;282:1561-7. 